\title{
Greek milk price decomposition
}

\section{Fotios Symeonidis*}

\author{
Hellenic Open University, \\ Aristotelous 18, 26335, Patras, Greece \\ Email: fsymeonidis@gmail.com \\ *Corresponding author
}

\section{Dikaios Tserkezos}

\author{
Department of Economics, \\ Faculty of Social, Economic and Political Sciences, \\ University of Crete, \\ Campus, Gallos, 741-00, Rethymno, Crete, Greece \\ Email: tserkezd@uoc.gr
}

\begin{abstract}
The aim of this paper is to analyse the Greek cow milk farm gate price, compare it with German and Irish prices and make an out of sample forecast for the year 2017. For this purpose, the milk price time series are modelled using the state space methods and they are decomposed into a trend, a seasonal and a cyclical component. The results show that there is an increase in the price fluctuations. The Greek milk price becomes more seasonal and cyclical while the duration of the cycles is relatively stable. Finally, conclusions are drawn about the connection of the cycles of the milk price time series and the milk production and quotas.
\end{abstract}

Keywords: milk price; Greece; state space model; SSM; forecasting; Kalman filter; cycle estimation.

Reference to this paper should be made as follows: Symeonidis, F. and Tserkezos, D. (2020) 'Greek milk price decomposition', Int. J. Decision Sciences, Risk and Management, Vol. 9, Nos. 1/2, pp.55-82.

Biographical notes: Fotios Symeonidis studied Veterinary Medicine at the Aristotle University of Thessaloniki and received his BA Honours degree in Veterinary Medicine, upon completion of ten semesters of study. He has been working since then in many different fields concerning large animal medicine, small animal medicine and public health. In 2017, he received his MBA Diploma at the Hellenic Open University.

Dikaios Tserkezos is a Professor of Econometrics and Computation at the University of Crete, Department of Economics. He has obtained his Bachelor in Business Administration from the Economic University of Piraeus, his Mc in Econometrics from the Department of Econometrics University of Manchester, and his $\mathrm{PhD}$ in Econometrics from the University of Piraeus. His research, professional and teaching interests are in the areas of applied econometrics using techniques of temporal disaggregation, corporate finance, portfolio management, risk management, asset pricing, and financial modelling. 


\section{Introduction}

Price volatility of the agricultural products is very important, both for the consumer and for the producer. High variations in agricultural prices have significant effects in the demand and supply chain. Extreme price fluctuations are not acceptable by the involved members due to the high importance and necessity that agricultural products constitute in the well-being of humans. Price has been always an indicator and information transmitter about the market. All the involved parties make decisions based on the price. Suppliers decide whether to increase production if prices are high or decrease production if prices are too low. Consumers, respectively, decide the quantity for purchase according to the price. Policy makers determine when to intervene or generate a new policy according the price signals of the market. Understanding the behaviour of the price time series is essential for the decision making.

Understanding price behaviour will help make better forecasts of the future prices and thus make better and more specific policies. Better forecasting means less uncertainty and better decision making for the involved parties (Hansen and $\mathrm{Li}, 2017$ ). Common agricultural policy (CAP) reforms have the perspective that price fluctuations are desirable as they are required in the decision process of the involved parties. However, if price fluctuations are not predictable or increasing in amplitude, then investments are reduced or high amount of resources are lost due to poor predictability. The unexpected shocks are those which produce uncertainty not the predicted ones.

The agricultural sector across EU has vast differences in farming methods and consumer products and is regulated through the CAP. Important changes have been made in the recent years towards the direction of deregulation, by abandoning the logic of price stabilisation and embracing the income stabilisation.

The purpose of this article is to examine the price volatility of Greek cow milk farm gate price before and after the Luxembourg Agreement in 2003, in comparison with Ireland and Germany.

Greece is the country under investigation and is compared with Ireland and Germany because no prior examination of farm gate milk price with a state space model (SSM) has been done. The production system of Ireland is very peculiar having the highest seasonality among the EU member states (MS). On the other hand, Germany is the biggest EU milk producer in volume.

Greece cow's milk production represents $0.4 \%$ of the total production of EU-28 (Eurostat, 2017). The milk products market in Europe is disparate and can be divided into two categories: liquid milk and processed milk like cheese. Greece belongs to the first category where most of the milk production is sold as drinkable milk (68.2\%), like most of Mediterranean countries apart from Italy; the UK is also a liquid milk market (53.14\%). Germany, France, Netherlands and Italy fall in the second category (Eurostat, 2017). $21 \%$ of the delivered Greek milk is processed to acidified milk like yoghurt. The rest milk quantity is processed to mostly cheese $(3.9 \%)$, cream $(2 \%)$ and others $(4.9 \%)$.

In this research work, the data used are time series of monthly milk price obtained by the EU milk observatory (European Milk Market Observatory, 2017). The milk price of Greece, Germany and Ireland are examined due to the structural differences they have. A method of structural time series is used in order to decompose the price in a trend, a seasonal, a cyclical and an irregular component. Through a division of pre and after 2004 policy change a comparison is made and its impact on the price volatility of milk is analysed. 
The results will be of value for the dairy producer, the dairy industry managers and the policy makers. The supply chain can make more correct decisions and forecasts of the milk price. The policy makers understand the implications and the effectiveness of a new policy. The main limitation of the article is the subjective division of milk price time series into two periods, where all policy changes have taken place immediately after 2004. The reason for that was that the research work should be in compliance with other research papers of similar work (Bergmann et al., 2015). Another limitation is the use of a univariate time series and not including other variables other than past price values. SSM can easily implement other variables like explanatory variables, but this attribute was not used in this article.

\section{Literature review}

Hunt and Kern (2012) used peak to peak analysis to examine the US milk price. They point out that the cycles presented during the 1990s ended and today are more erratic. O'Connor et al. (2015), using descriptive statistics, examined the price fluctuations of dairy commodities. They conclude that the percentage change in a three-month span in EU SMP prices prior 2007 was usually 5\%, but after 2007 the changes were of $15 \%$ or more.

There are also many empirical methods and models for time series decomposition. Those methods, which are discussed below, decompose a time series into different time periods due to their different statistical approaches. A classification of the methods has been proposed by Chagny and Döpke (2001) (as cited in Ladiray et al., 2003). The notion of those methods is to decompose the time series into a permanent component (trend) and a temporary component (cycle).

Skarżyńska et al. (2013) examined the consumer milk price fluctuations from January of 2001 to July of 2013 using the Hodrick and Prescott filter. They conclude that there is an upward trend, seasonal and cyclical fluctuations. The cyclical component is more prominent of the seasonal. The authors found that after 2011, there are noticeable changes in the fluctuations of the seasonality. The fluctuations became bigger in amplitude and the seasonal cycle has a sharp low and bimodal peaks. Finally, a remark is made about the cycle, where the upward phase of the cycle is a mean for counterbalancing the low prices during the downward phase of the cycle. There are multiple articles using the band pass filter. Erten and Ocampo (2013) using annual data of agricultural commodities price series, through the use of the band pass filter, decomposed them into trend and super cycles and found a slightly upward trend from 1865 to mid-1910s, then a long period of downward trend up until 1990s and from then on stabilisation. In the same period 1865 to 2010, three super cycles were identified of different period spans, and a cycle which undergoing right now, began in 2000s with a strong upward phase. Through descriptive statistics for the super cycles, they note that the mean real price of the commodities of each super cycle is getting smaller. They, also note the presence of shorter cycles which are also important in the price formation, especially in the interwar period. A similar filtering method of statistical decomposition is used by Harvey et al. (2012) at an aggregate real price index of annual non-oil commodities for the period 1900 to 2010 . They report an increase both in the periodicity and in the fluctuations of the super cycles. Contrary, the findings for the short cycles 
suggest a decrease in periodicity. The authors believe it is due to high volatility of the prices of the commodities. Pfaffenzeller (2002) used Beveridge and Nelson decomposition in agricultural commodities. The time series indexes were annual data from 1900 to 1998. Among his findings was that the permanent shock is greater in wheat while the opposite is true for the rice, meaning that more structural policy measures should be taken. Reinhart and Wickham (1994) applying also Beveridge and Nelson decomposition and SSM at quarterly data indexes of food commodities from 1957 to 1993 conclude with both methods that the volatility in food commodities has increased. By measuring the persistence of shock, they found that permanent shocks are important for food commodities ( $73 \%$ of the variance of yearly changes) and it took 12 years for the Cochrane ratio (Cochrane, 1988 as cited in Reinhart and Wickham, 1994) to converge. The trend follows the prices, meaning that permanent shocks are more important in the price decomposition. Another aspect which they point out is that even in transitory shocks, if they persist for long periods, then more core effective measures should be applied. Cuddington (1992) used Beveridge-Nelson decomposition on beef real prices (in logs) having unit roots from 1900 to 1992 . He concluded that the trend was statistically insignificant and all innovations were of permanent character and no cyclical component was found. Bergmann et al. (2015) have decomposed monthly milk nominal prices series from January 1995 to December 2013 into trend, seasonal and cyclical components, using a SSM. The purpose of the authors was to examine how the 2003 CAP reform has impacted the milk price. After policy reform there is greater seasonality, higher volatility, price converge, and the cycles are persistent and become smaller. Also comparing the US cycle with the EU cycles, seems, the US cycle to lead, by some months. Nicholson and Stehpenson (2015) used quarterly data from 1996 to 2014 of nominal US milk price in a SSM. Also, an explanatory variable (feed cost) was introduced in the model. They report that the period of the cycle was 39 months. Price movements were attributed by $30 \%$ to the cyclical component. The damping factor (see later explanation) of the cycles was strong. Rezitis et al. (2015) examined the quarterly nominal price of wheat and rice from January of 1983 to April of 2012 with a SSM. Wheat price variation is explained mostly from two cycles, the long cycle being the most important. The periods of the wheat cycles are 1.75 years and 7.7 years. Both of the cycles have a strong persistence. Rice price variation is explained mostly from the irregular part and then from the two cycles. Rice cycle components have duration of 1.1 years and 15.5 years. Damping factor (see later explanation) of the long cycle is 0.814 but for the short cycle is 0.515 . Through the decomposition, the author gives an interpretation of the wheat and rice price time series fluctuations. In detail, the author believes that the long cycle of wheat is connected with the grain stocks but the 2008 volatility of rice price time series is not explained by the cycles, so the shock should have been an exogenous. Moreover, the irregular term is explained by a market restriction decision, the imposition of export quota. Rezitis and Sassi (2013) used SSM to decompose the commodity food price index. The data used are monthly logs from November of 1992 to October of 2012. The time series is decomposed into deterministic trend (level only) and seasonal effect, two cycles, explanatory variables crude oil and the US real effective exchange rate as logarithms and intervention variables. Lagged values of endogenous variables were also included in the model. The cycles become more prominent after 2003 and on. Hansen and Li (2017) looking for a relationship between feeds (commodities) and world milk monthly nominal prices for the time period 2002 January to 2013 December, used wavelet MRA in order to decompose the two time series into different frequencies and then compare them. The 
time series are decomposed into five periods (trend, 32, 16, 8, 4 months). After 2007, milk prices start to fluctuate more drastically and both the feed and milk fluctuations become more intense. Hansen and $\mathrm{Li}$ (2017) report a shorter business cycle in comparison to Nicholson and Stehpenson (2015) and Bergmann et al. (2013). The authors attribute those differences to different time periods examined, different time series and different geographical area. The presence of the cycle, according to the author could be due to feed cost changes but further research is required. Finally, he reports that there are also intra-annual cycles of 4 to 8 months.

Detailed information about the above methodologies can be found in Ladiray et al. (2003) and in Symeonidis (2017).

\section{Model}

The methodology which will be followed is according to Bergmann et al. (2015) and the analysis was performed with the usage of the software program Oxmetrics ${ }^{\circledR}$ (Doornik, 2009) and STAMP ${ }^{\circ}$ of Koopman et al. (2010).

Originally, SSMs were developed by engineers to control linear systems (Reinsel, 2012). The idea is that the time series have also an underlying structure, composed of unobservable components.

We used a SSM because the time series does not need to be stationary. The time series is decomposed directly into its unobserved components trend (level, slope), cycle, seasonality, irregular each of which is modelled separately (e.g., the components can be stochastic) before incorporated into the model. In contrast, Box-Jenkins approach the trend and seasonality are eliminated by differencing. The SSM is flexible due to it can incorporate parameters with time dependency. Another advantage is the handling of missing data or the incorporation of two data sources of different periodicity (e.g., monthly, quarterly). A large model is easier created and handled; a forecast is easily produced due to the nature of the model (Kalman filter); and explanatory variables are easily incorporated into the model (Durbin and Koopman, 2012; Rezitis et al., 2015).

The SSM is composed of at least two equations. The observation or measurement equation and the unobserved or state equations, which decompose the time series into trend, seasonal and cyclical components.

$$
\begin{array}{ll}
y_{t}=\mu_{t}+\gamma_{1, t}+\beta_{t} x_{t}+\lambda_{t} w_{t}+\varepsilon_{t} & \varepsilon_{t} \sim \operatorname{NID}\left(0, \sigma_{\varepsilon}^{2}\right) \\
\mu_{t+1}=\mu_{t}+v_{t}+\xi_{t} & \varepsilon_{t} \sim \operatorname{NID}\left(0, \sigma_{\xi}^{2}\right) \\
v_{t+1}=v_{t}+\zeta_{t} & \varepsilon_{t} \sim \operatorname{NID}\left(0, \sigma_{\zeta}^{2}\right) \\
\gamma_{1, t+1}=-\gamma_{1, t}-\gamma_{2, t}-\gamma_{3, t}+\omega_{t} & \omega_{t} \sim \operatorname{NID}\left(0, \sigma_{\omega}^{2}\right) \\
\gamma_{2, t+1}=\gamma_{1, t} & \\
\gamma_{3, t+1}=\gamma_{2, t} & \\
\beta_{t+1}=\beta_{t}+\tau_{t} & \tau_{t} \sim \operatorname{NID}\left(0, \sigma_{\tau}^{2}\right) \\
\lambda_{t+1}=\lambda_{t}+\rho_{t} & \rho_{t} \sim \operatorname{NID}\left(0, \sigma_{\rho}^{2}\right)
\end{array}
$$


where $y_{t}$ are the time series values, $\mu_{t}$ is the level of the trend, $v_{t}$ is the slope of the trend, $\gamma_{1, t}$ is the seasonal component, $x_{t}$ is the explanatory variable with $\beta_{t}$ its coefficient, $w_{t}$ is the intervention variable treated as a dummy variable, with $\lambda_{t}$ its coefficient.

In the state space form the role of least squares computations are represented by the Kalman filter. Thus, in state space methods in comparison with the regression model, the parameter estimates are acquired not by aiming at minimising the observation errors and their variance $\sigma_{\varepsilon}^{2}$ but by minimising the prediction errors $e_{t}$ and their variances $v_{t}$ (Commandeur and Koopman, 2007). More details for the Kalman filter and the state space equations are in Harvey (1989), Commandeur and Koopman (2007), Symeonidis (2017) and Forero (2012).

The trend $\left(\mu_{t}\right)$ is the permanent component and gives the general direction in the long-term. The trend can be decomposed to level $\left(\mu_{t}\right)$ and slope $\left(v_{t}\right)$ and either one can be deterministic or stochastic. The level is similar to the intercept of linear regression. The latter determines the level of the regression line, so the level component does similarly (Commandeur and Koopman, 2007). If the level is deterministic, then it is like an intercept, but in a SSM the level can be stochastic, meaning it can change from point to point in time by a value of $\xi_{t}$, which is the level disturbance. The slope in classical linear regression is the equivalent of the coefficient of the independent variable. Thus, the slope $\left(v_{t}\right)$ (drift) determines the gradient of slope and is stable if it deterministic and it can change over time if it is stochastic (Commandeur and Koopman, 2007). The seasonal components $\left(\gamma_{t}\right)$ are used if there is a stable pattern repeating in the same period each year. The number of the state equations for the seasonal effect depends where the data are monthly, quarterly or semi-annually collected, but the summation of the seasonal effect is zero due to their cyclicality:

$$
\sum_{j=0}^{s-1} S_{t-j}=0
$$

A cycle $\left(c_{t}\right)$ is also a stable pattern repeating interannually. The model can have many cycles of different duration, where each cycle represents different duration of cycles (Commandeur and Koopman, 2007).

$$
\left[\begin{array}{c}
\psi_{t} \\
\psi_{t}^{*}
\end{array}\right]=\rho_{\psi}\left[\begin{array}{c}
\cos \lambda_{c} \sin \lambda_{c} \\
-\sin \lambda_{c} \cos \lambda_{c}
\end{array}\right]\left[\begin{array}{c}
\psi_{t-1} \\
\psi_{t-1}^{*}
\end{array}\right]+\left[\begin{array}{c}
\kappa_{t} \\
\kappa_{t}^{*}
\end{array}\right], t=1, \mathrm{~K}, T
$$

where $\rho_{\psi}$ is the damping factor, $\lambda_{c}$ is the frequency in radians, $\kappa_{t}, \kappa_{t}^{*}$ are two mutually uncorrelated normally and independently distributed disturbances with zero mean and common variance $\sigma_{\kappa}^{2}$.

The damping factor takes values $0 \leq \rho_{\psi} \leq 1$. The higher the value, the more persistent is the cycle. If $\rho_{\psi}=1$, then the cycle is constant. If $\rho_{\psi}<1$, then the cycle fluctuations are decreasing in the long-term (Ladiray et al., 2003). The frequency takes values $0 \leq \lambda_{c} \leq \pi$ and the period is given by $2 \pi / \lambda_{c}$.

The seasonal component is the yearly fluctuation of the time series and the cycle is those fluctuations of the milk price time series, which occur for longer than a year (Rezitis et al., 2015).

Also, the model can be extended with explanatory variables $\left(x_{t}\right)$, lagged values of the dependent variable and intervention variables $\left(w_{t}\right)$. The latter are used when either sudden change of the price happen and are considered as outliers. Another type of intervention 
variable is either when the change is considered permanent, so it is either a level shift or slope shift. The intervention variables $\left(\lambda_{t}\right)$ can be added to the model as dummy variable $\left(w_{t}\right)$ where $w_{t}$ equals zero all the time until the point where the permanent change happens and thereafter the value of the dummy variable changes to one. If it was only an outlier, then the dummy variable would be all the time period equal to zero except the time point where the outlier value exists and the dummy variable changes to one (Commandeur and Koopman, 2007). The explanatory variable $\left(x_{t}\right)$ is added to the model with a coefficient $\left(\beta_{t}\right)$ as in classic linear regression (Commandeur and Koopman, 2007).

An explanatory variable is used in the model when the time series cannot be explained by the existing components of the model and thus a better fit of the model is created. In the present article, no explanatory variable is incorporated in the view that if any major explanatory variable created a shock in the time series, all countries would have been impacted by it. An exogenous shock, besides a shock due to policy change, still does not help the goal of the present article which is to examine the policy intervention on the milk price, although a better forecast would have incurred. Finally, the irregular term $\left(\varepsilon_{t}\right)$ is used to compensate for the unexpected events or events which cannot be explained by the model, and thus an exogenous, unidentified factor might exist (Rezitis et al., 2015).

The model in this article is composed of a stochastic trend of a random walk with drift, a seasonal component and one or two cycles; where is needed, a deterministic component is selected. The difference between a stochastic component with a very low variation and a deterministic component is small. In each time series, only two outliers as described in Commandeur and Koopman (2007) are added. The different components of the model are estimated simultaneously by a maximum likelihood method.

\section{Data}

The data chosen for the empirical analysis are monthly farm gate milk price time series per 100 litres of milk from January 1977 to February 2017 of Greece, Germany, and Ireland, obtained from the Milk Market Observatory of EU ${ }^{1}$ (European Milk Market Observatory, 2017), which are available for free online.

The yearly milk production and quotas of the above countries were obtained for the period $1999 / 2000$ to $2014 / 2015$ by the European commission Press Releases (http://europa.eu/rapid/press-release_IP-11-1204_en.htm?locale=en) and the European Commission (https://ec.europa.eu/agriculture/milk-quota-end_en) (EU Quota Table, 2017) and for the period 1990/1991 to 1998/1999 from the European Commission and the Special Report 6/2001 of the Court of Auditors (Court of Auditors, 2001).

In Figure 1, the nominal historical monthly farm gate milk prices are presented per 100 litres of Greece, Ireland, Germany and EU average. We can see that the Greek price time series in the beginning are at the same level with the other countries but some distinct characteristics emerge. Firstly, the price does not depict a strong annual fluctuation with peaks and troughs as other countries do. Secondly, there is a clear departure from the average milk prices from the start of the first decade of 2000. Thirdly, there is a tendency of Greek prices to stabilise above the mean EU milk prices with an upward trend and they have less price variation in comparison of those of the other countries. Lastly, we cannot conclude if the Greek milk prices are in accordance with the 
mean price level, in the beginning of 2017, since they seem similar but only because average milk price levels are at a peak, similar to the two previous situations in November of 2007 and October of 2013.

Figure 1 Nominal historical milk prices at farm gate per 100 litres (see online version for colours)

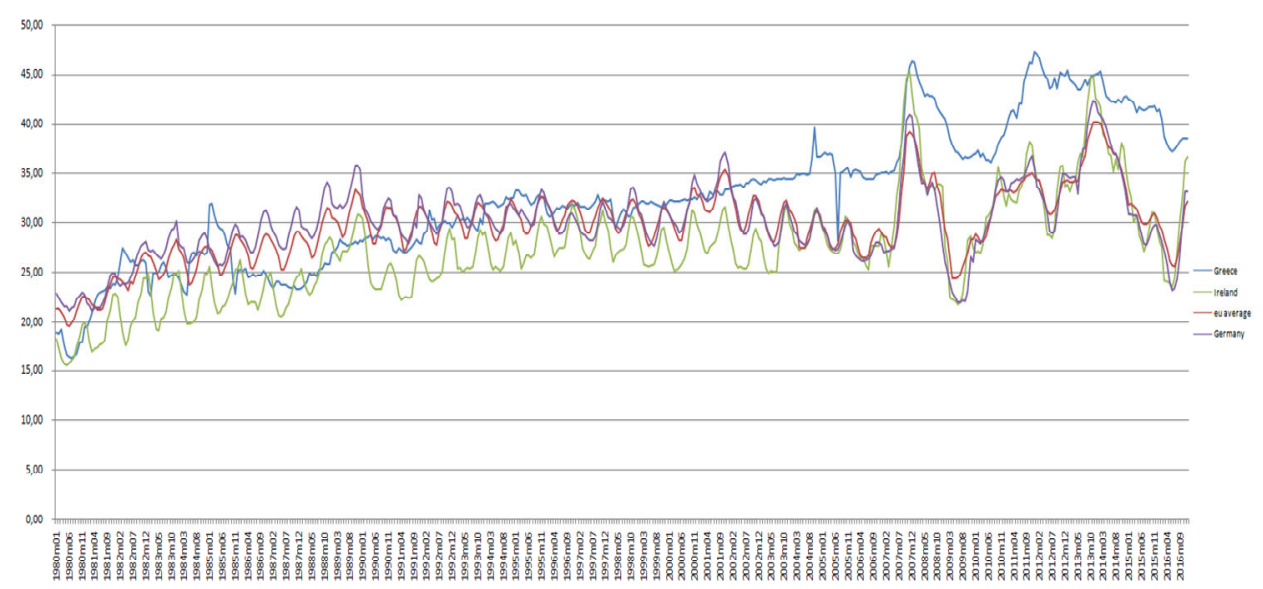

Note: Greece (blue line), Ireland (green line), EU average (red) and Germany (purple line).

Source: European Milk Market Observatory (2017), own calculations

Figure 2 Greece milk quotas* and annual milk production delivered** (see online version for colours)

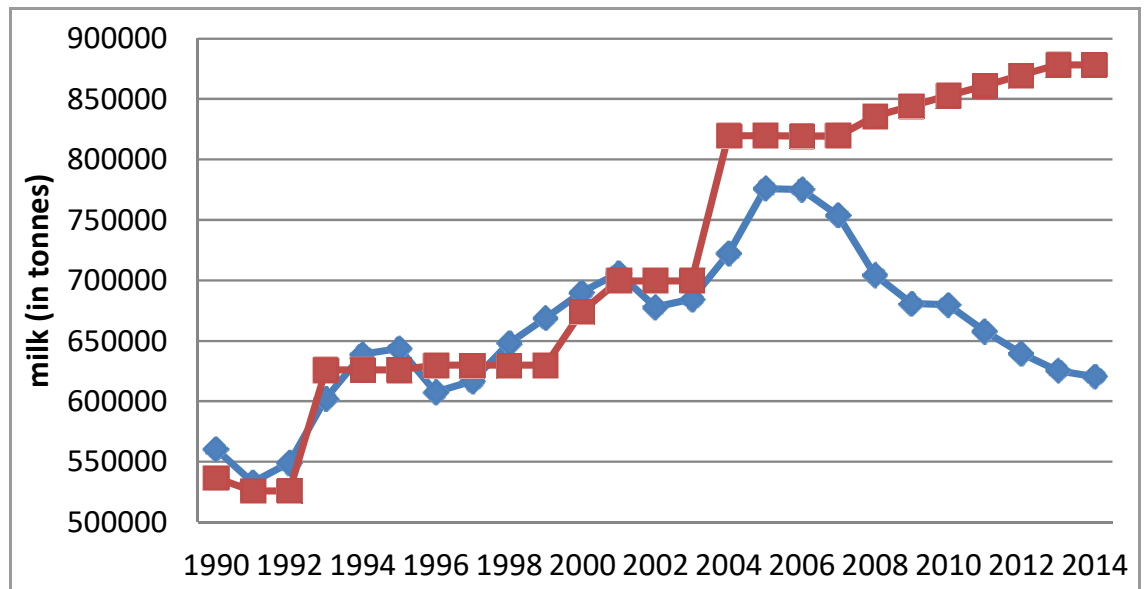

Note: *Red line and **blue line.

Source: 1990-1998: 6/2001 Special Report, 1999-2014: European Commission Press Releases, own calculations 
Figure 3 Ireland milk quotas* and annual milk production delivered** (see online version for colours)

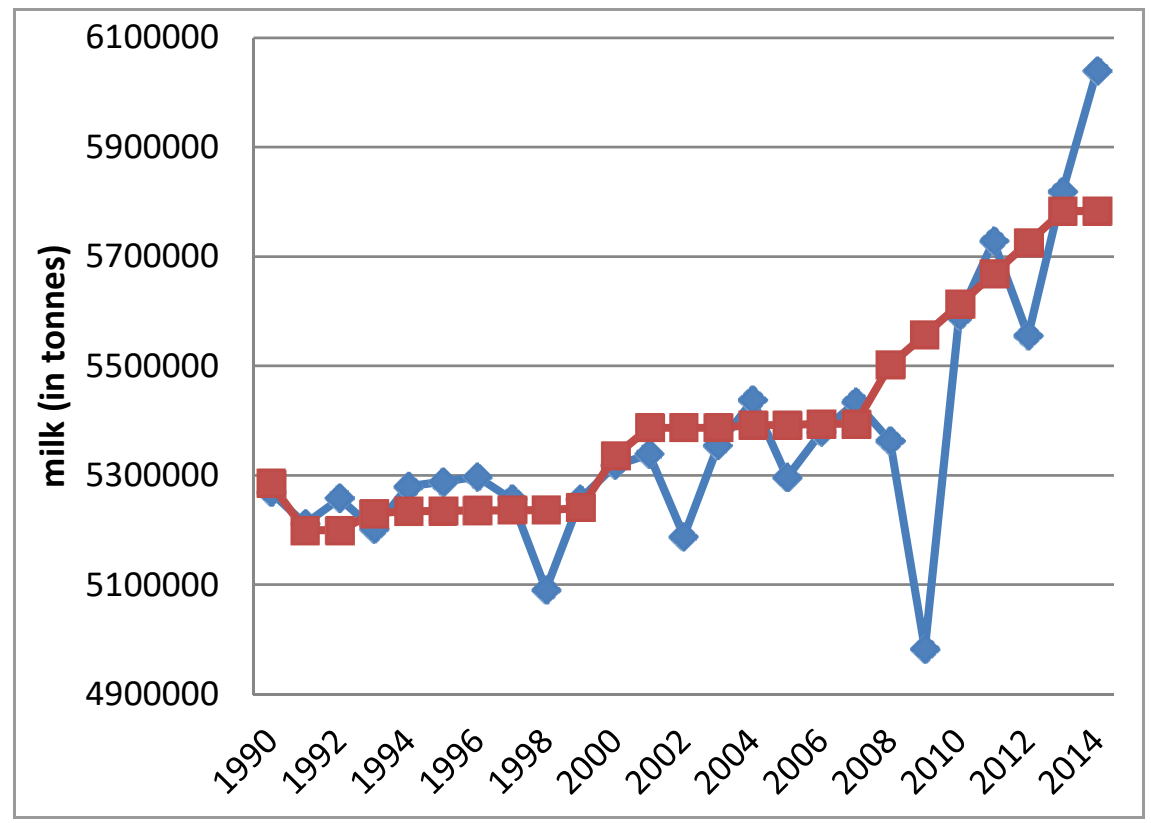

Note: *Red line and $* *$ blue line.

Source: 1990-1998: 6/2001 Special Report, 1999-2014: European Commission Press Releases, own calculations

Figure 4 Germany milk quotas* and annual milk production delivered** (see online version for colours)

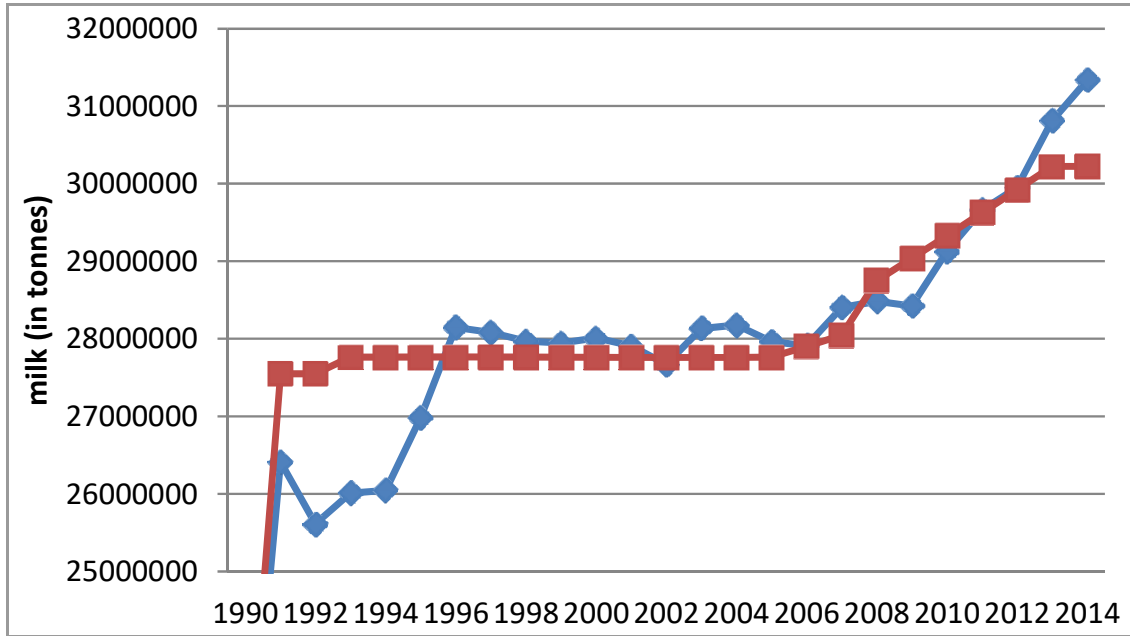

Note: *Red line and **blue line.

Source: 1990-1998: 6/2001 Special Report, 1999-2014: European Commission Press Releases, own calculations 
In Figure 2, we can see the Greek milk two special quotas increases, in 2001 which had happened in two stages, in 2001 and in 2004. In 2008, the 'soft landing'2 quota increases commence. Also, the years 1998/1999, 1999/2000 overproduction is observed, possibly due to the animal improvement by importing breeds of increased milk production capability. The most notable observation is that from 2004/2005 period, the Greek milk production is well below the quota limit. This is important if it is taken into account that Greek milk market is not self-sufficient. At the beginning of the period, this is due to the quota regime but this does not seem to change from 2004 onward, meaning other factors contribute to the low national milk production, perhaps the increased farm gate milk price, in comparison to other countries. Another note is that during the food commodities crisis in 2007-2008 and the financial crisis from 2009 onward, the national milk production was decreasing, with possible stabilisation in 2014 milk production. Figure 3 and Figure 4 depict the quotas and the national milk production of Ireland and Germany, respectively.

\section{Results}

The descriptive statistics of the data are given in Table 1. A notable difference is the mean value change of Greece. A second observation is the change of the minimum and maximum prices; the EU average, Ireland and Germany have lower minimum and higher maximum recorded prices. This means that there is also an increase in the coefficient of variation (CV). The lower CV in Greece is 0.036093 in the period 1996-2003 and increases in the following period to 0.09815 . Thus, the price fluctuation has increased after the 2003 reform, but again in Greece is still lower than of the EU average.

The time series are decomposed to their components by the smoothing algorithm according to Koopman et al. (2010). Their components are the trend which is decomposed to a level and a slope, the seasonal component and the cycle. Finally, the fluctuations which cannot be explained by the model constitute the irregular component (Rezitis et al., 2015). The smaller the irregular component is, the better the time series is explained by our model.

Through the results of Table 2 , it is decided whether a component of the model of each examined country will be stochastic or deterministic. Thus, for the period 1996-2003, the German milk price time series is decomposed into a deterministic level, because of the low variance. The slope component is stochastic having a variance of 0.000736687. Similarly, the cycle is also stochastic with a variance 0.0719583. Finally, the seasonal component is deterministic. Thus, the German milk price time series fluctuations are affected mostly by the slope and cycle component. The seasonal and level fluctuations are predictable. Irish milk price time series have stochastic seasonal and cycle components and deterministic slope and a relative stochastic level. Thus, the trend of Ireland's time series has very small changes and price fluctuations are mostly due to the cycle and seasonal component. Finally, for the same time period, Greece time series is decomposed to a stochastic level with a deterministic slope and seasonality. The cycle is stochastic. 
For the period 2004-2016, the German milk price time series has a stochastic slope, the seasonal component is deterministic and the cyclical component is consisting of two cycles which they are stochastic. Similarly, Ireland has a deterministic seasonal component. The trend is also deterministic, leaving only the cycle to be stochastic. The Greek milk price time series trend is decomposed into a deterministic level and a stochastic slope. The seasonal component is stochastic as it is also the cycle.

The cycle further is characterised by its damping factor and its period. Generally, all the time series have a strong persistent stationary cycle, which are slowly damped, meaning that the subsequent cycle will be of the same characteristics as the previous one. In Greece the first period, 1994-2003, the cycle is not as persistent as those of the other countries and is faster damped. Also, Germany has two cycles in the second period, 2004-2016. The cycle 1 is similar to the cycles that the other countries consist of. The cycle 2 is a small cycle. Both cycles are persistent. The period of the cycles is from 32 to 45 months. There is an exception for Greece in the first period where the period of the cycle is half (16 months) in comparison to that of the other countries for the same period.

The graphical representation of the model for each country is given in Figures 5 to 6 , it is notable the four peak seasonal component of Greece milk price time series in the period 1996-2003.

Figure 5 The state space components of Ireland's, Germany's and Greece's milk price time series 1996 to 2003 (see online version for colours)
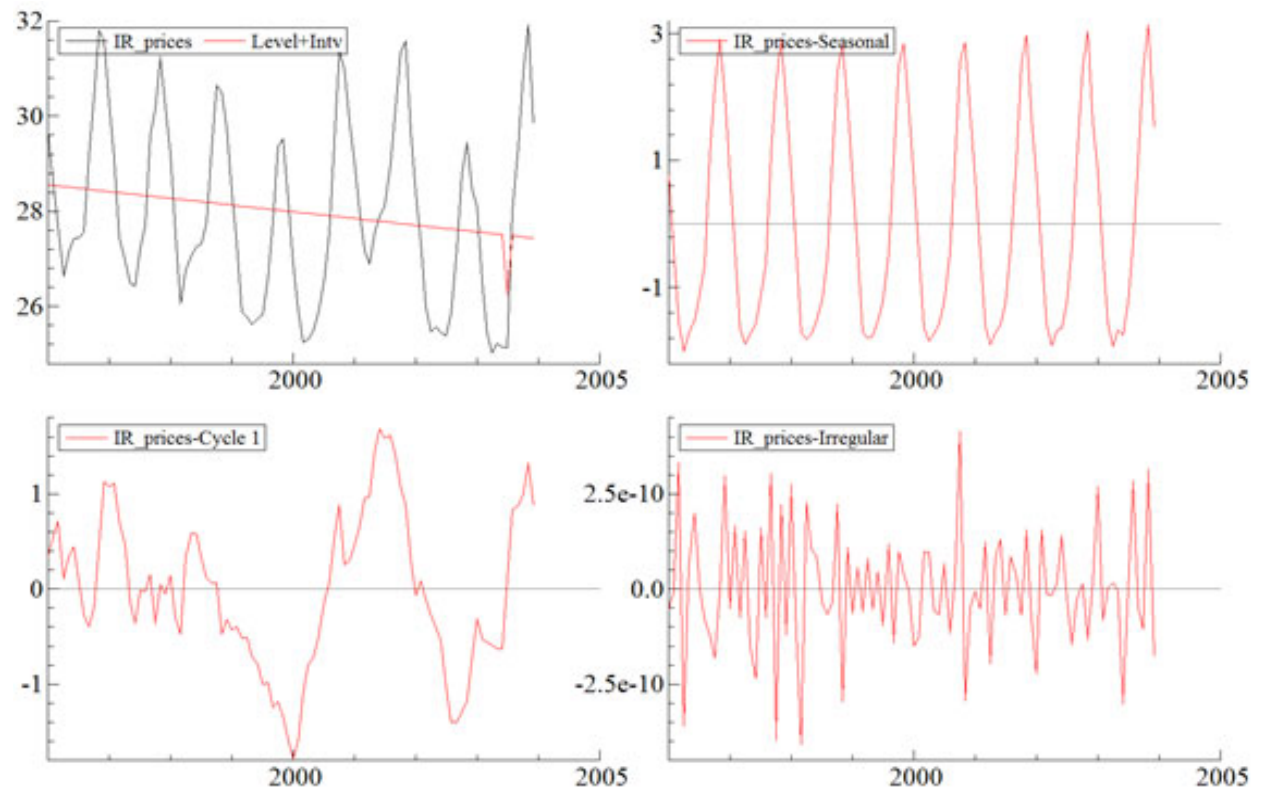

Note: In the top left, the time series with the level component, in the top right the seasonal component, in the bottom left, the cycle component and bottom right, the regular component.

Source: Own calculations 
Figure 5 The state space components of Ireland's, Germany's and Greece's milk price time series 1996 to 2003 (continued) (see online version for colours)
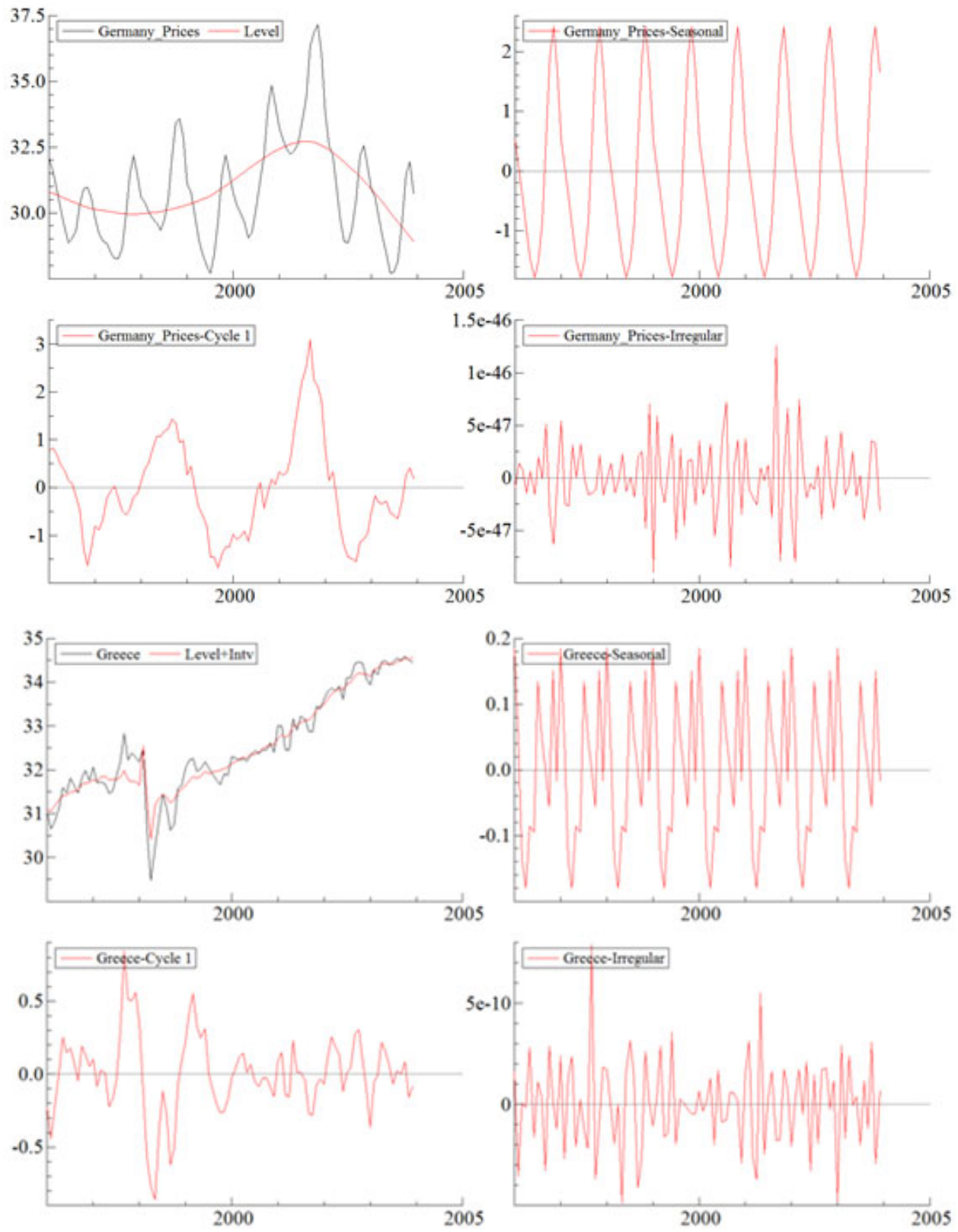

Note: In the top left, the time series with the level component, in the top right the seasonal component, in the bottom left, the cycle component and bottom right, the regular component.

Source: Own calculations 
Table 1 Statistical measures of the sample

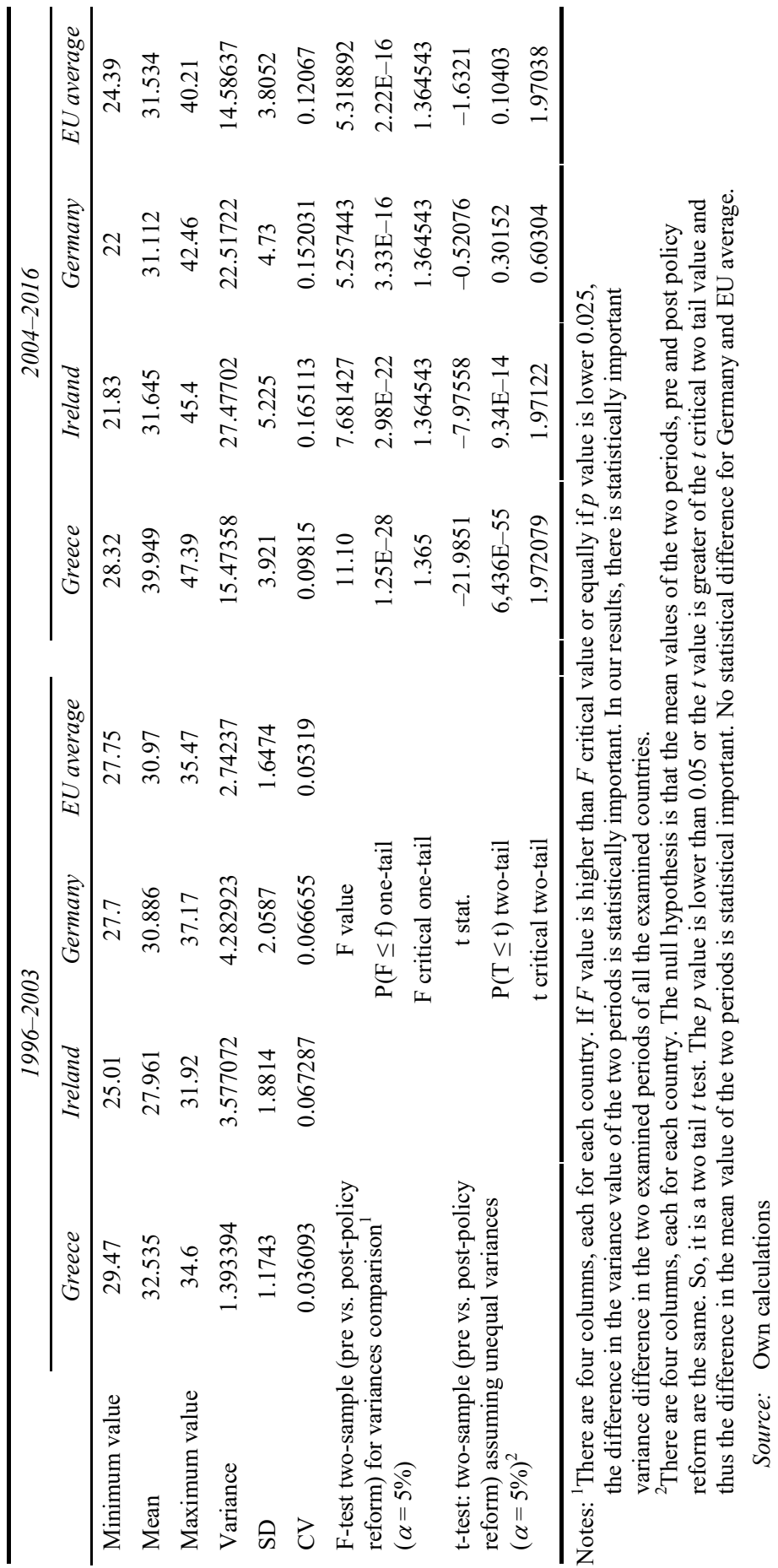


Table 2 The variance of level, slope, seasonal, cycle 1, cycle 2 and the irregular component of the spate space model of each time series are presented

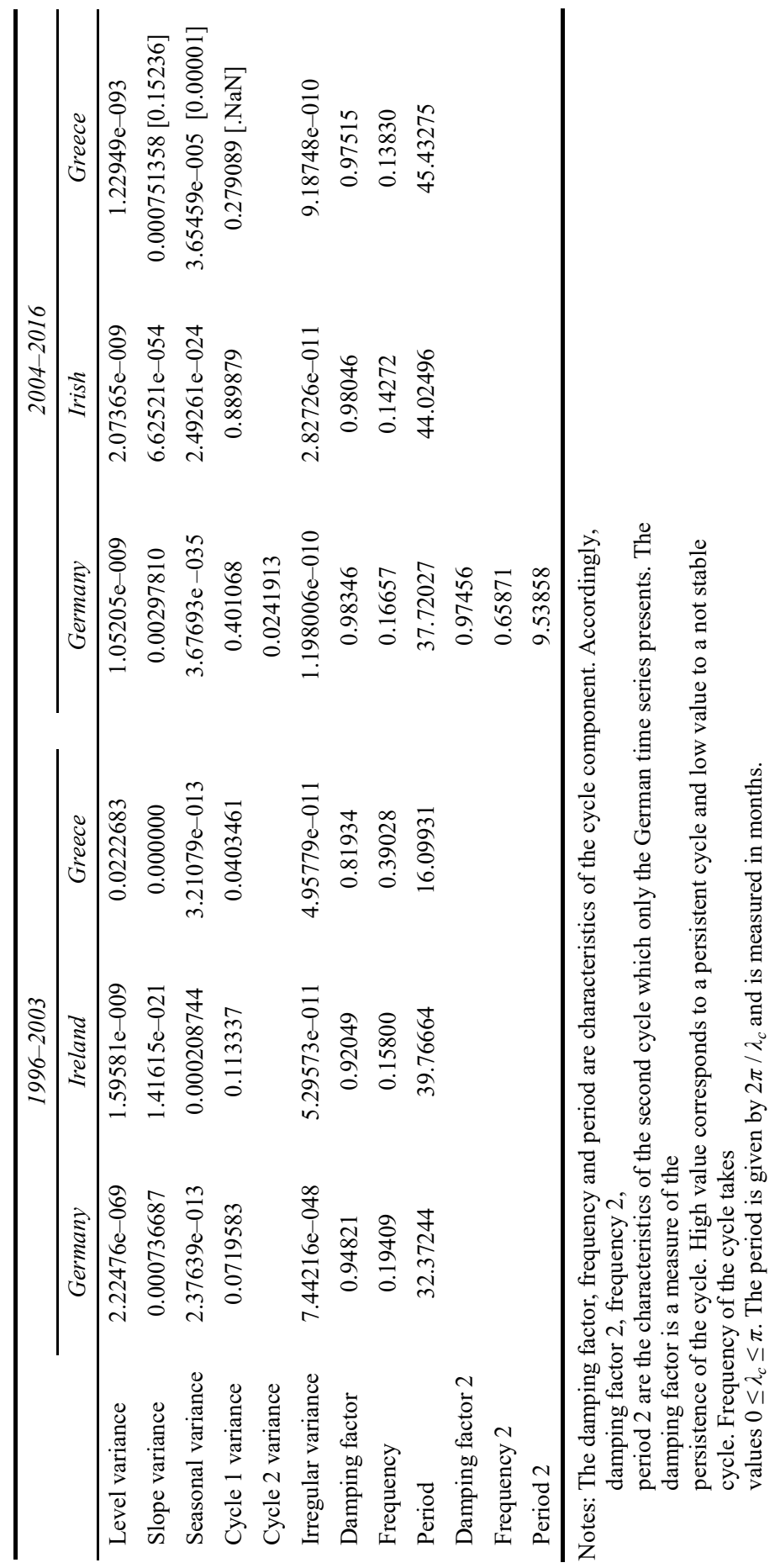


From Table 3, the criteria of independence, homoskedasticity and normality are satisfied, except the normality test for the German and Greece 2004-2016 milk price time series and Greece homoskedasticity test for both periods. Table 4 shows the goodness of fit base on the residuals for each time series.

Table 3 Diagnostics tests ${ }^{1}$ for the SSMs of Greece, Ireland and Germany for the first period, 1996-2003, and the second period, 2004-2016

\begin{tabular}{|c|c|c|c|c|c|}
\hline & \multirow{2}{*}{$\frac{\text { Independence }^{2}}{Q(24,6)}$} & \multicolumn{2}{|c|}{ Autocorrelation } & \multirow{2}{*}{$\frac{\text { Homoscedasticity }^{3}}{H(27,27)}$} & \multirow{2}{*}{$\frac{\text { Normality }^{4}}{\chi_{2}^{2}}$} \\
\hline & & $r(1)^{5}$ & $r(24)$ & & \\
\hline \multicolumn{6}{|l|}{ 1996-2003 } \\
\hline Germany & $\begin{array}{c}21.869 \\
{[0.290824]}\end{array}$ & 0.14428 & -0.10771 & $1.9709[0.041784]$ & $\begin{array}{c}3.9823 \\
{[0.136538]}\end{array}$ \\
\hline Ireland & $\begin{array}{c}14.768 \\
{[0.737224]}\end{array}$ & 0.015805 & 0.12044 & $\begin{array}{c}0.67506 \\
(1.481349)^{6} \\
{[0.156671]}\end{array}$ & $\begin{array}{c}4.8122 \\
{[0.090166]}\end{array}$ \\
\hline Greece & $\begin{array}{c}10.455 \\
{[0.940815]}\end{array}$ & -0.037015 & -0.0018499 & $\begin{array}{c}0.40792(2.45146) \\
{[0.011559]}\end{array}$ & $\begin{array}{c}2.6110 \\
{[0.271037]}\end{array}$ \\
\hline Critical value & $30.1^{7}$ & $\pm 0.2^{8}$ & \pm 0.2 & $2.16^{9}$ & $5.99^{10}$ \\
\hline \multicolumn{6}{|l|}{ 2004-2016 } \\
\hline Germany & $\begin{array}{c}14.065 \\
{[0.779889]}\end{array}$ & 0.035153 & -0.11660 & $1.6072[0.112029]$ & $\begin{array}{l}15.650 \\
{[0.004]}\end{array}$ \\
\hline Ireland & $\begin{array}{c}24.501 \\
{[0.177631]}\end{array}$ & 0.038741 & -0.034324 & $\begin{array}{c}0.88055 \\
(1.135654) \\
{[0.37175]}\end{array}$ & $\begin{array}{c}2.6204 \\
{[0.269766]}\end{array}$ \\
\hline Greece & $\begin{array}{c}22.969 \\
{[0.23871]}\end{array}$ & 0.051734 & -0.073494 & $\begin{array}{c}0.45870(2.18) \\
{[0.23753]}\end{array}$ & $\begin{array}{c}7.9345 \\
{[0.018925]}\end{array}$ \\
\hline Critical value & 30.1 & \pm 0.16 & \pm 0.16 & 1.78 & 5.99 \\
\hline
\end{tabular}

Notes: ${ }^{1}$ The standardised prediction errors of the model should satisfy, with decreasing order of importance, the independence, homoscedasticity and normality test, which are applied at the residuals.

${ }^{2}$ The independence test is checked through the portmanteau Box-Ljung $Q(p)$ test statistic based on the first $p$ autocorrelations.

${ }^{3}$ It is checked whether the variance of the errors corresponding the first third part of the series is equal to the variance of the errors corresponding to the last third part of the series.

${ }^{4}$ It is a Bowman and Shenton test which follows a $\chi^{2}$ distribution with two degrees of freedom at $5 \%$ level.

${ }^{5} r(1)$ is the lag 1 (or first order) residual autocorrelation and $r(24)$ is lag 24 residual autocorrelation.

${ }^{6}$ In the parenthesis () is the reciprocal of $H(h), 1 / H(h)$ in order to make a right tailed test.

${ }^{7}$ For Box-Ljung test statistic lag $24, \chi^{2}$ critical value at 5\% level and 19 degrees of freedom is 30.1 .

${ }^{8}$ It is the correlation value that corresponds for a two tailed $t$-test with 95\% confidence interval and for 96 observations in period 1006-2003 and 156 observations for the period 2004-2016, respectively.

${ }^{9}$ It is the critical value of an two tailed F test with $5 \%$ level and $(27,27)$ degrees of freedom.

${ }^{10} \chi^{2}$ critical value at $5 \%$ level and 2 degrees of freedom is 5.99 . 
Figure 6 The state space components of Ireland's, Germany's and Greece's milk price time series 2004 to 2016 (see online version for colours)
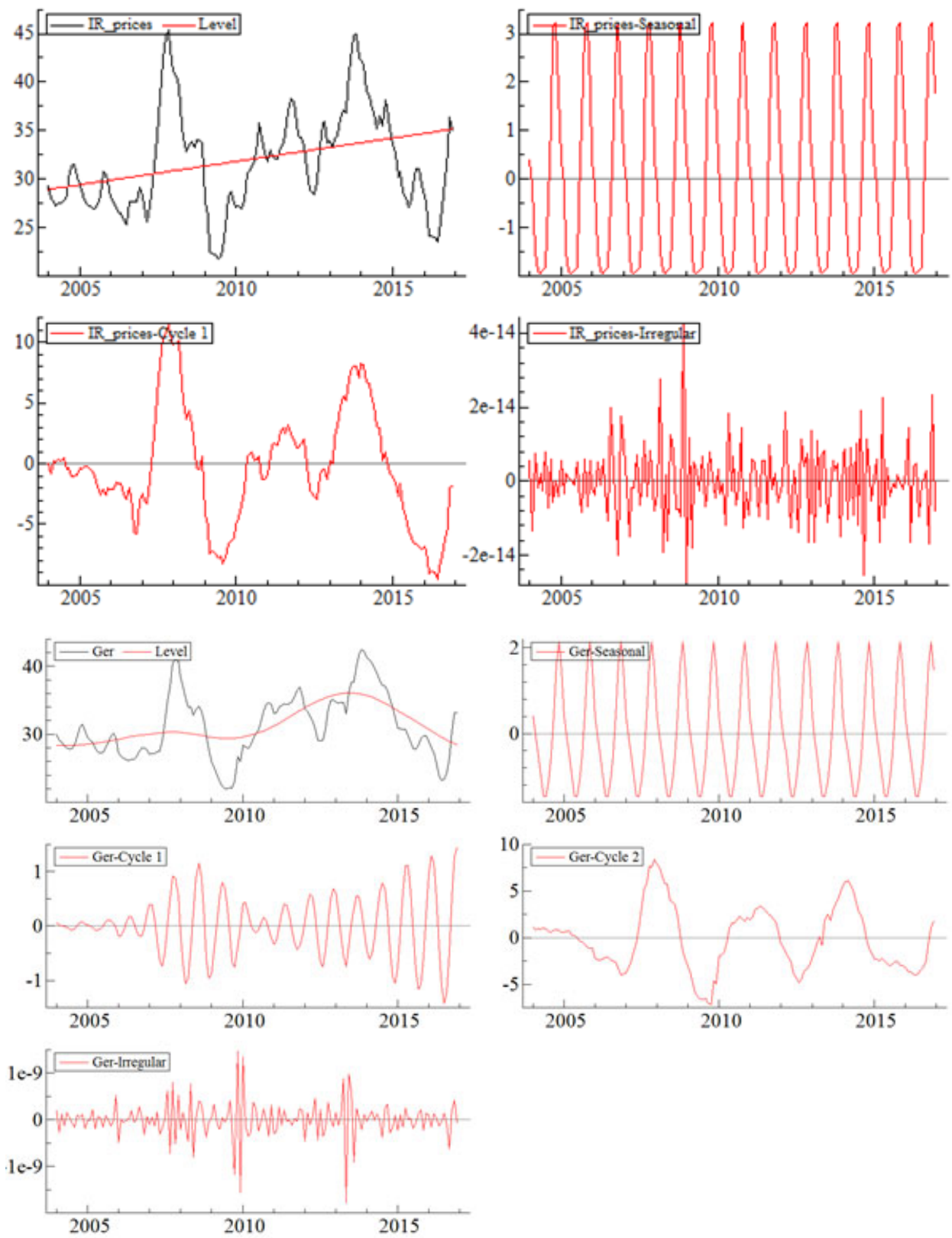

Note: In the top left, the time series with the level component, in the top right, the seasonal component, in the bottom left, the cycle component and right, the regular component.

Source: Own calculations 
Figure 6 The state space components of Ireland's, Germany's and Greece's milk price time series 2004 to 2016 (continued) (see online version for colours)
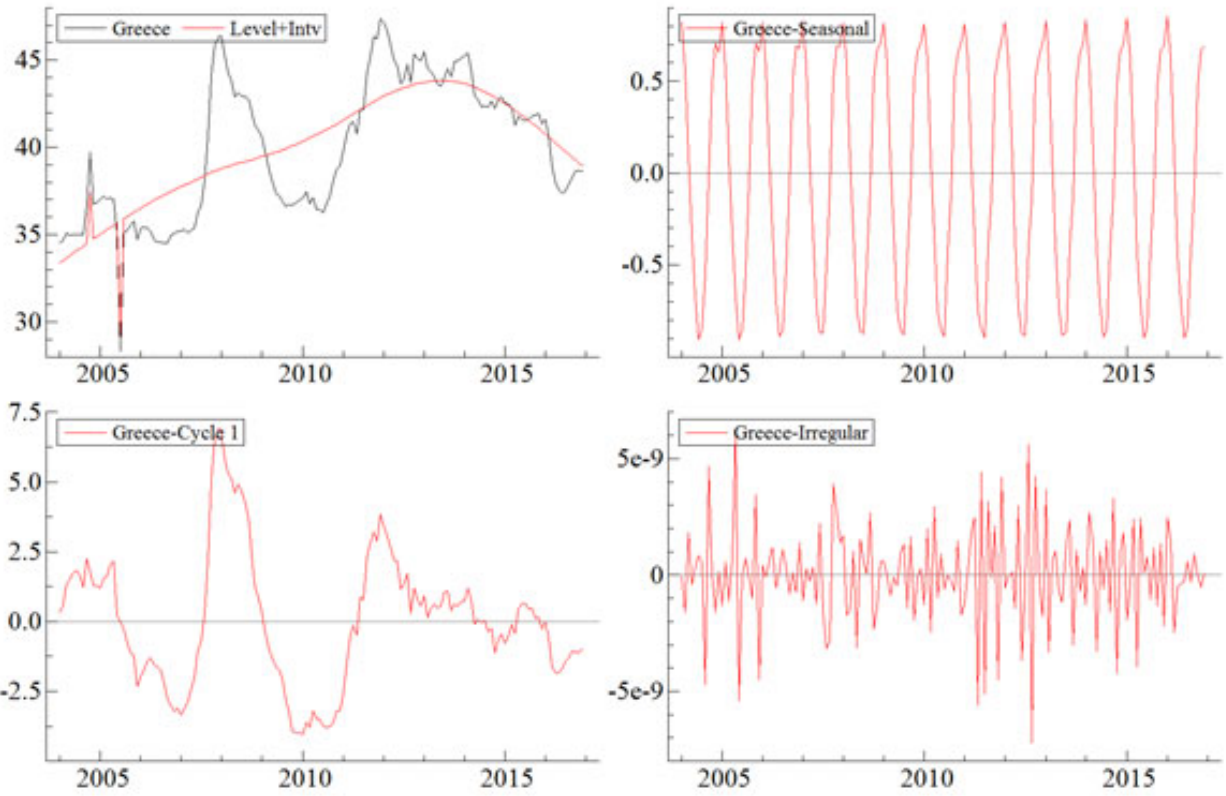

Note: In the top left, the time series with the level component, in the top right, the seasonal component, in the bottom left, the cycle component and right, the regular component.

Source: Own calculations

Table 4 Goodness of fit based on the residuals for each time series of Greece, Ireland and Germany for the first period, 1996-2003, and the second period, 2004-2016

\begin{tabular}{lcccccc}
\hline & $R^{21}$ & $R_{s}^{22}$ & $R_{d}^{23}$ & $\begin{array}{c}\text { Ratio p.e.v. } \text { in squares }^{4} \\
\text { in s. }\end{array}$ & AIC & BIC \\
\hline Germany & 0.978 & 0.34703 & 0.87446 & 0.77178 & -1.9353 & -1.5613 \\
Ireland & 0.96007 & 0.28457 & 0.86723 & 1.0466 & -1.4865 & -1.0858 \\
Greece & 0.93855 & 0.049644 & 0.21479 & 1.4109 & 0.20951 & 0.48322 \\
\hline
\end{tabular}

Notes: ${ }^{1}$ The coefficient of determination $R^{2}$, measure of goodness of fit, can be used for a structural time series but when the series are stationary with no trend or seasonality.

2If the model has a seasonal component, then $R_{s}^{2}$ is used instead of $R^{2}$, and $R_{d}^{2}$.

So the model is measured against a random walk (stochastic level) plus drift (stochastic slope) and fixed seasonal. Thus, a seasonal mean is subtracted from $\Delta y t$ (Koopman et al., 1995).

${ }^{3} R_{d}^{2}$ is used when the series show a trend. So the variance of first differences $\Delta y t$ is used. The model is measured against a random walk plus drift (Koopman et al., 1995).

${ }^{4} \mathrm{~A}$ good model has a ratio close to unity. It is the ratio of prediction error variance (PEV) divided by the squared mean deviation of the prediction error (Koopman et al., 1995). 
Table 4 Goodness of fit based on the residuals for each time series of Greece, Ireland and Germany for the first period, 1996-2003, and the second period, 2004-2016 (continued)

\begin{tabular}{lcccccc}
\hline & $R^{21}$ & $R_{s}^{22}$ & $R_{d}^{23}$ & $\begin{array}{c}\text { Ratio p.e.v./m.d. } \\
\text { in squares }\end{array}$ & AIC & BIC \\
\hline 2004-2016 & & & & & & \\
\hline Germany & 0.97531 & 0.42106 & 0.60565 & 1.2808 & -0.32688 & -0.053174 \\
Ireland & 0.97004 & 0.41608 & 0.68797 & 1.088 & 0.1054 & 0.4182 \\
Greece & 0.97911 & 0.67690 & 0.73304 & 1.151 & -0.82971 & -0.5169 \\
\hline
\end{tabular}

Notes: ${ }^{1}$ The coefficient of determination $R^{2}$, measure of goodness of fit, can be used for a structural time series but when the series are stationary with no trend or seasonality.

${ }^{2}$ If the model has a seasonal component, then $R_{s}^{2}$ is used instead of $R^{2}$, and $R_{d}^{2}$.

So the model is measured against a random walk (stochastic level) plus drift (stochastic slope) and fixed seasonal. Thus, a seasonal mean is subtracted from $\Delta y t$ (Koopman et al., 1995).

${ }^{3} R_{d}^{2}$ is used when the series show a trend. So the variance of first differences $\Delta y t$ is used. The model is measured against a random walk plus drift (Koopman et al., 1995).

${ }^{4} \mathrm{~A}$ good model has a ratio close to unity. It is the ratio of prediction error variance (PEV) divided by the squared mean deviation of the prediction error (Koopman et al., 1995).

Table 4 shows information related to goodness of fit. $R_{d}^{2}$ is the coefficient of determination that should be taken into account for a SSM with a stochastic level, slope and a seasonal component. Ratio p.e.v./m.d. in squares in simple terms is a comparison of the variance of the prediction errors to the squared deviations from the mean and a robust model should have a ratio close to one (Koopman et al., 1995).

\section{Discussion}

In the period 1996-2003, the trend of each country is different. Greece has only a stochastic level, Germany a stochastic slope and Ireland has both components of the trend deterministic. Thus, the mean level of Greece changes over time, where in contrast Germany has a change in price growth rate. Graphically, by examining the trend, in Ireland it is decreasing from 1996 to 2003 and in Germany it increases from 1998(1) to 2001(8) and then decreases until 2004. In Greece, the trend is clearly upwards. By considering the quotas applied during that period, the self-sufficiency in milk and the relative prices, a reasonable explanation could be, that the mean milk price and consequently the mean dairy farmer income was increasing in Greece in contrast to that of other two countries where the mean value of milk price remained stable. The trend of Germany and Ireland graphically are similar to those reported in Bergmann et al. (2015).

The seasonal component is stochastic only in Ireland milk price time series. In fact, the amplitude is the highest. Peak to trough (maximum drawdown) is $€ 5.15 / 100 \mathrm{~kg}$, followed by Germany deterministic seasonal component, €4.21/100 kg. Greece has four peaks and only a small part of the price variation can be attribute to price fluctuation. The seasonal price variation is $€ 0.37 / 100 \mathrm{~kg}$. Highest price is in January and the lowest is 
in April, followed by the second peak in May, a third peak in July and a fourth peak in November. In Germany, the seasonal component has its lowest point at 1997(6) and highest at 1996(11). Ireland's lowest value is at 1996(4) in and highest in 2003(11). Greece seasonal component may have this pattern, because of the small amplitude of the seasonal pattern.

The cycle pattern in the three countries examined is stochastic. The series cycle pattern of Greece milk price time series is not clear. Only one small cycle is present from $1997(5)$ to $1998(11)$ and a smaller one from 1998(12) to 2000(1). The damping factor is 0.8193 . The variance of the cycle is $€ 0.123 / 100 \mathrm{~kg}$ and its amplitude is $€ 1.71 / 100 \mathrm{~kg}$, with the highest price in $1997(9), € 0.85 / 100 \mathrm{~kg}$ and the lowest $1998(5)-€ 0.86 / 100 \mathrm{~kg}$. Germany seems to present the highest amplitude $€ 4.78 / 100 \mathrm{~kg}$, Ireland's cycle has an amplitude of $€ 3.47 / 100 \mathrm{~kg}$.

By examining the cycles, the milk production and quotas, the authors believe that in the period 1996-2003, Ireland and Greece follow the cycle pattern, whereas Germany despite having the highest cycle amplitude does not follow the cycle pattern. This could be due to the fact that the MS had already reached the quota limit or due to the 2000 CAP reform, where an increase in the quota limit was aimed and a phenomenon like the seat belt implementation may have happened (Harvey, 1993), or even an external factor could have created the increased cycle amplitude. The authors are not aware of any food commodity crisis in 2000s that could produce the cycle similar to the 2007-2008 crisis. Moreover, the cycles are present in different time periods. Greece's cycle is present from $1997(5)$ to 1998(11) and a smaller one from 1998(12) to 2000(1), Ireland's cycle is from $1998(11)$ to 2000(12) and Germany from 1998(1) to 2000(7) and 2000(11) to 2003(9). It is important to note how much irregular is the Greek first cycle in comparison with the other countries. Also, the cycles in Ireland and Greece seems to be produced when there was a quota increase in 2000 and 2001.

The duration of the cycles is different between the countries. Greece's cycles last for 16 months in comparison to Germany's, 32.37 months and Ireland's 39.77 months. The literature refers that these cycles are due to the time needed for the dairy farmer to produce new livestock and consequently increase milk production sufficiently (Bergmann et al., 2015; Nicholson and Stehpenson, 2015). The authors believe that this is true in a closed economy. Maybe, Greece's cycles are small because dairy cows of high production capabilities were imported, thus reducing the duration needed for increasing the milk volumes.

A normalised measure, used by Bergmann et al. (2015) is to divide amplitude of the seasonal and cyclical component by the mean of the time series, in order to find how much of the price variation is due to these components. By applying this, at the aforementioned cycles of the period 1996-2003, the results are presented in Table 5. Greece price variation attributed to the cycle and seasonal component is the lowest of the three countries. Overall, Germany and Ireland have the same price variation, but Ireland is mostly seasonal whereas Germany's is sufficiently equally shared between cycle and season.

In the period 2004-2016, Ireland still has a deterministic trend but the direction is upwards. Germany's trend remains a stochastic slope, with a deterministic seasonal component and two cycles. Cycle 1 is similar in duration to that of the other countries. Cycle 2 is a cycle with small duration, of 9.54 months. That means that apart from the seasonal price variation, a second type of price variation is attributed to other factors. 
Greece has changed its trend from a stochastic level to a stochastic slope, meaning that from a changing mean price is now turning to a change in the price growth around a stable moving level.

Table 5 Percentile price variation attributed to cyclical and seasonal component in the cycles present from 1996 to 2003

\begin{tabular}{lccc}
\hline Cycle duration & Cyclical & Seasonal & Cyclical + Seasonal \\
\hline 1997(5)-1998(11) GR & $5.25 \%$ & $1.12 \%$ & $5.52 \%$ \\
$1998(12)-2000(1) \mathrm{GR}$ & $2.51 \%$ & $1.12 \%$ & $2.44 \%$ \\
$1998(11)-2001(12) \mathrm{IR}$ & $12.40 \%$ & $17.48 \%$ & $23.55 \%$ \\
$1998(1)-2000(7) \mathrm{DE}$ & $10.07 \%$ & $13.63 \%$ & $20.43 \%$ \\
$2000(11)-2003(9) \mathrm{DE}$ & $15.03 \%$ & $13.63 \%$ & $24.45 \%$ \\
\hline
\end{tabular}

Source: Own calculations

By examining the output in Figure 6, we see that in Greece the level is going upwards from January of 2004 to June of 2013. After this peak, it starts to decline from July of 2013 till the end of the examined time series 2016(12), closing at $€ 38.93 / 100 \mathrm{~kg}$ milk. The milk price farm change due to the level fluctuation was from $€ 33.36 / 100 \mathrm{~kg}$ milk to above $€ 43.83 / 100 \mathrm{~kg}$ milk. The slope which is stochastic has a small importance in the price variability. The amplitude of the slope is from $-€ 0.17 / 100 \mathrm{~kg}$ to $€ 0.14 / 100 \mathrm{~kg}$, a total of $€ 0.31 / 100 \mathrm{~kg}$. It begins in 2004(1) positively and relatively steady up until 2011(5) where a clear downward course is evident, passing to negative in 2013(6) and staying like this until 2016(12). Ireland's trend is linear with upwards direction. Germany has a stable level up to 2010(10), then it goes upwards until 2013(9), where it becomes a downwards trend until the end. Thus, the mean level of Germany milk price is lower than the Ireland's price. This difference in level is attributed to the model of Germany, where the cycle 2 has also an important role in price variation. Greece's general level is above the aforementioned countries. The upward trend, present since the beginning of the time series at 1996 ends in July of 2013.

The seasonal component is shown in Figure 6 and Greece's seasonality is further analysed in Figure 7. Greece has an almost steady peak to trough amplitude (maximum drawdown) of about $€ 1.75 / 100 \mathrm{~kg}$. Germany (€3.62/100 kg) and Irish $(€ 5.15 / 100 \mathrm{~kg})$ farm gate milk price seems to be more seasonal than Greece's, with the Irish showing the highest seasonal variation. In Greece, the seasonal component is bimodal, with peaks in November and January. The following years, at December the price drop is disappearing and the single highest value is in January. The lowest value is in June. During the years, August is the month which has changed most. From a negative $€ 0.56 / 100 \mathrm{~kg}$ declined to negative $€ 0.4 / 100 \mathrm{~kg}$. This was in compensation mostly on the month of April. Further, the negative peak of the seasonality during the period 2007 to 2012, changed from June to July. The months which are above the trend line are October to February. March and September are close to the trend line. From April to August, the price drops below the trend line.

Overall, the seasonal variation has increased in Ireland and Greece and has decreased in Germany in comparison to the period 1996-2003. The decrease in Germany could be due to change in production method, which become more intense. By considering the production system in Greece which has remained unchanged from 1996-2016, we can 
assume that the increase in the seasonality is probably due to imported pressure of the European prices and due to the intensification of the production.

Figure 7 Seasonal component decomposed into the months of the year from 2004 to 2016 (see online version for colours)
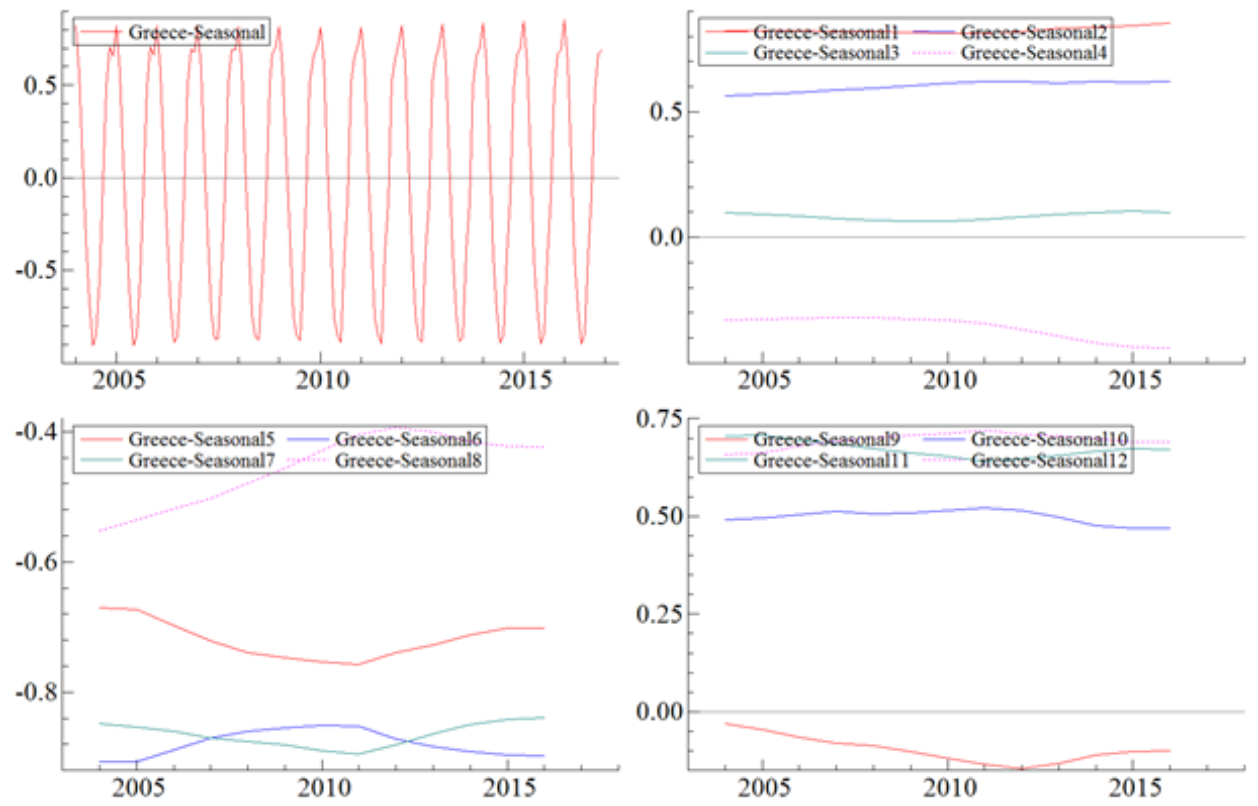

Source: Own calculations

Ireland has more price fluctuation due to its more seasonal milk production pattern in comparison to Greece, where the milk production throughout the year is relatively steady, keeping the prices also steady.

The Greek cycle has a period of 45 months (3.78 years). The Irish cycle has a period of 44 months (3.66 years) and the German 37.72027 months (3.14 years). The damping factor is less than one, so the cycle is stationary (Mills and Patterson, 2009). A high value of the damping factor, $(\rho)$, means that the cycle is persistent and it depicts what part of a shock will appear, in the long run, in the subsequent cycles, and eventually to the trend (Rezitis and Sassi, 2013). Greece has the longest cycle. Generally, the duration of the cycles of 2004-2016 in comparison to the ones of 1996-2003 is relatively stable. This is in contrast with Bergman's findings, who suggest that the period of the cycle in 2004-2016 is becoming smaller in comparison with the period 1995-2004 due to market response. In Greece, moreover the authors believe that the cycles in 1996-2003 are a half cycle due to the import of pregnant animals. Cycle 2 of Germany resembles the gestation length of a cow. This is the fastest way for a producer to respond to market signals. He can program the number of cows being inseminated in accordance with the market signals. These fluctuations are low at the beginning of the period but become more apparent during the 2007-2008 food commodity crisis and during 2014-2016.

In Greece, the variance of the cycle is $€ 5.68$ and the maximum amplitude is $€ 10.97 / 100 \mathrm{~kg}$ of the second cycle, the years of the commodity crisis during 2007 to 2010. The examined time series comprised of three full cycles and one being under 
development. The other two cycles are comprised of smaller amplitudes of $€ 5.6 / 100 \mathrm{~kg}$ and $€ 4.98 / 100 \mathrm{~kg}$.

Using the normalised measure, of dived amplitude of the seasonal and cyclical component by the mean of the time series, we have the following results (Table 6).

Table 6 Percentile price variation attributed to cyclical and seasonal component in the cycles present from 2004 to 2016

\begin{tabular}{lccc}
\hline Cycle duration & Cyclical & Seasonal & Cyclical + Seasonal \\
\hline 2004(1)-2007(7) GR & $11.54 \%$ & $1.41 \%$ & $12.95 \%$ \\
2007(8)-2011(5) GR & $27.08 \%$ & $4.01 \%$ & $31.09 \%$ \\
$2011(6)-2015(4) \mathrm{GR}$ & $9.86 \%$ & $4.08 \%$ & $13.94 \%$ \\
$2005(7)-2008(10) \mathrm{DE}$ & $39.36 \%$ & $11.42 \%$ & $42.72 \%$ \\
$2008(11)-2011(12) \mathrm{DE}$ & $33.51 \%$ & $11.42 \%$ & $37.98 \%$ \\
$2012(1)-2014(9) \mathrm{DE}$ & $34.39 \%$ & $11.42 \%$ & $37.66 \%$ \\
$2004(8)-2008(9) \mathrm{IR}$ & $54.37 \%$ & $16.27 \%$ & $61.44 \%$ \\
$2008(10)-2012(8) \mathrm{IR}$ & $36.28 \%$ & $16.27 \%$ & $48.27 \%$ \\
$2013(4)-2016(12) \mathrm{IR}$ & $56.12 \%$ & $16.27 \%$ & $71.56 \%$ \\
\hline
\end{tabular}

Source: Own calculations

Ireland has the highest cycle amplitude due to the cycle at 2013(4)-2016(12), after the food commodity crisis, $56.12 \%$. The overall impact of the cyclical and seasonal component is $71.56 \%$. This is an important increase in comparison with the pre-2004 period. The change is mostly due to the cyclical component. Similarly, in Germany the impact of the cycle has more than doubled. The seasonal component has slightly decreased its impact. In Greece, the seasonality has increase in the last two cycles. The cyclical impact has also a fivefold increased. The results are little lower than the literature; maybe due to model differences. In the period 2004-2016, there is more cycles present, and thus the price has more fluctuations.

By examining the cycles, the milk production and the quotas of 2004-2016 period, Ireland is under the quota limit and thus the milk production follows the cycle component. In Greece, milk production is following the cycle component more freely than Ireland. There is an increase in milk production in 2004, 2005 followed by a stable production in 2006 and a decline in 2007. In the years 2008, 2009 and 2010, there is a sharp decline in production. In 2011, the negative component of the cycle seems to prevail the positive period of the same cycle. In the following years up until 2014, there seems to be stabilisation in production. For Germany, by comparing the cycle with the yearly milk production, in 2005 and 2006, there is a milk production reduction followed by an increase in 2007 and then stabilisation in 2008 and again a decrease in 2009. From 2010 to 2014, there is an increase in production. In 2012 despite the negative cycle, there is an increase in production but with slower magnitude in comparison with the previous years.

The authors believe that Ireland and Germany depict the same behaviour as pre-2004, because the milk production is near the quota limit, and an increase of the quota is expressed in the milk price as a cycle. 


\section{Forecast}

Figure 8 shows the prediction plot of milk price in Greece, generated by the constructed model of Greece from January of 2004 to December of 2016. The period from January of 2015 to December of 2017 is used as an out of sample forecast. The prediction values for the period from January of 2015 to December of 2016 are very close to the real values of the same period and are within the prediction intervals (or forecast intervals) set at $\pm 1 \mathrm{RMSE}^{3}$ approximately $68 \%$ (Harvey, 1989). (Figure 8 top left). The plot where actual values are compared with the predicted values shows that the prediction values have a very good approximation of the real values. Finally, a CUSUM ${ }^{4}$ test (Figure 8 bottom left) is executed and is shown graphically; at $10 \%$ significance level it is a stable model. The CUSUM test examines through the cumulative sum of the standardised errors if they are random or a systematic bias exists and thus the model is unfit for forecasting. CUSUM $t$-test statistic is used, to examine whether the cumulative standardised errors are biased by examining the CUSUM test validity and if their sum falls in the significant intervals of $95 \%$ with 12 degrees of freedom. The results are shown as a plot at Figure 8 bottom right and at Table 8 . Finally, a chi-test is performed with 12 degrees of freedom (Table 7). The results are acceptable, the null hypothesis that the predicted values are no different of the actual values, holds.

Figure 8 Prediction graphics of Greece milk price (see online version for colours)
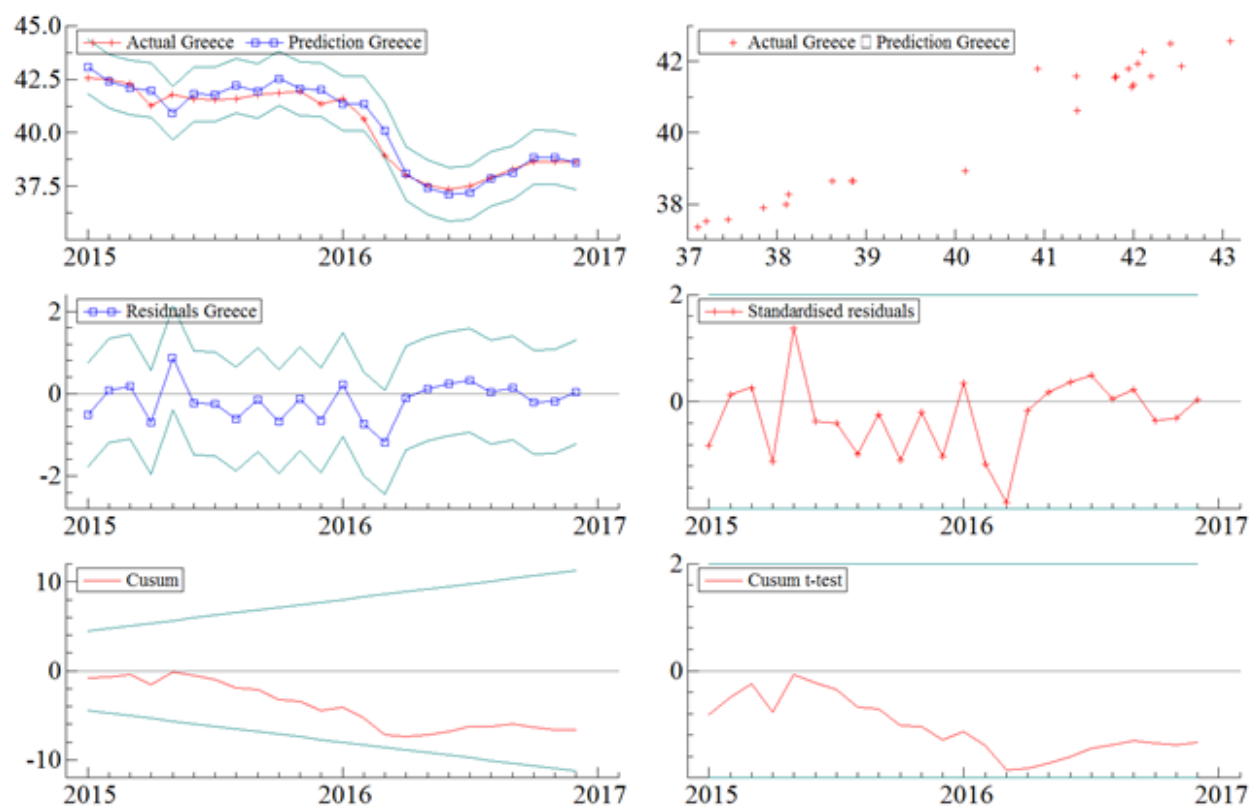

The forecasting method of a SSM is through the Kalman filter and the obtained values are referring after the end of the sample (Commandeur and Koopman, 2007). The sample period chosen is from June of 2004 to December of 2016 because the relative policy is still the same until today. 
Table $7 \quad$ Post-sample predictive tests

\begin{tabular}{lccc}
\hline & & Critical value & $p$ value \\
\hline CUSUM $t_{12}$ test & -0.6179 & $2.306^{1}$ & 0.5482 \\
$\chi_{12}^{2}$ test & 5.7860 & $21.026^{2}$ & 0.9265 \\
\hline
\end{tabular}

Notes: Level of significance $5 \%$.

${ }^{1}$ The null hypothesis is not rejected, thus no important deviation (breakaway) of the CUSUM is detected.

${ }^{2}$ The null hypothesis is not rejected, thus term of independency of the standardised prediction errors is satisfied.

For a good forecast the assumptions of normality, uncorrelation and homoskedasticity should hold. Given the empirical results for the Greek milk price time series for the examined period, the obtained model is good (see Table 3 and 4).

The chosen time horizon is 12 months. A comparison can be made between the obtained results of forecast with the true values of the period January of 2017 to June of 2017 obtained by the milk market observatory of EU.

The forecast diagram, shown in Figure 9, with 68\% ( \pm 1 RMSE) prediction interval, for the Greek milk price for the year 2017 is a fairly stable price having the highest value in $2017(1), € 38.7863 / 100 \mathrm{~kg}$ and the lowest in $2017(6) € 36.9746 / 100 \mathrm{~kg}$. The level is downward monotonically starting from the highest value $2017(1) € 38.764 / 100 \mathrm{~kg}$ to $€ 36.91942 / 100 \mathrm{~kg}$ in $2017(12)$. The amplitude of the seasonal component is $€ 1.74 / 100 \mathrm{~kg}$, which is stable in comparison with the earlier years. The slope component in not part of the forecast and thus it kept stable at $-€ 0.1678 / 100 \mathrm{~kg}$. Finally, the upcoming negative part of the cycle which the model has calculated that is underdevelopment from 2015(5) will be fulfilled in 2017(6). The cycle has already passed it lowest negative value. The forecast values with their prediction intervals are given at Table 8 .

Table 8 Forecasts with 68\% prediction interval (or forecast interval) from period 2016(12) forwards

\begin{tabular}{lcccc}
\hline & Forecast & Stand. err. & Left bound & Right bound \\
\hline 1 & 38.78634 & 0.63127 & 38.15507 & 39.41760 \\
2 & 38.53663 & 0.95227 & 37.58436 & 39.48890 \\
3 & 38.00324 & 1.24940 & 36.75383 & 39.25264 \\
4 & 37.45535 & 1.53377 & 35.92157 & 38.98912 \\
5 & 37.18354 & 1.81375 & 35.36979 & 38.99729 \\
6 & 36.97461 & 2.08559 & 34.88901 & 39.06020 \\
7 & 37.01182 & 2.35224 & 34.65958 & 39.36407 \\
8 & 37.39893 & 2.60883 & 34.79011 & 40.00776 \\
9 & 37.68273 & 2.85744 & 34.82529 & 40.54017 \\
10 & 38.19703 & 3.09404 & 35.10299 & 41.29108 \\
11 & 38.33103 & 3.31953 & 35.01150 & 41.65056 \\
12 & 38.26570 & 3.52616 & 34.73955 & 41.79186 \\
\hline
\end{tabular}


Figure 9 Forecast (see online version for colours)
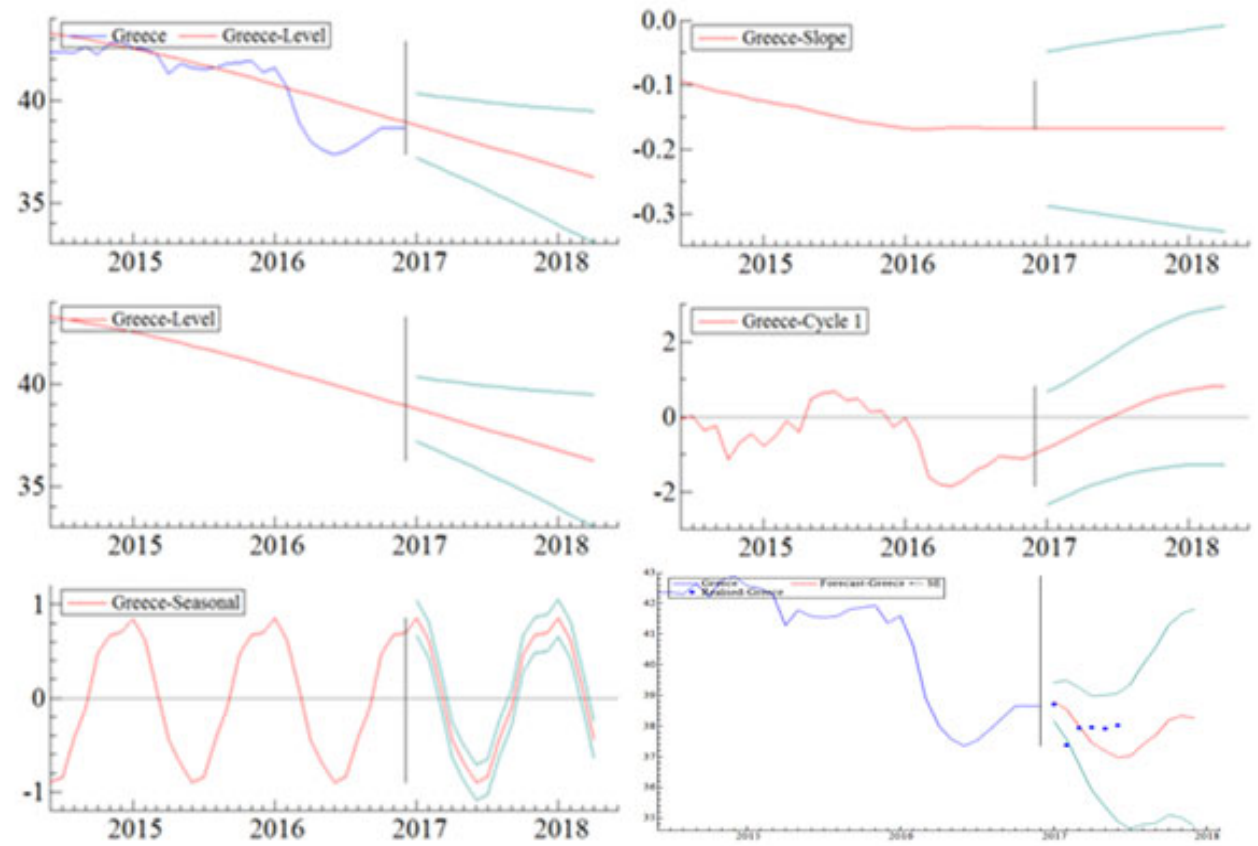

Notes: In the top left, trend (red line) and real values (blue line). In top right, the slope which its forecast is deterministic. In middle left, the level which is monotonically downward. In middle right, the cycle component forecast. In bottom left, the seasonal component and, in the bottom, right the forecast is given (red line) and real values until 2017(6) (blue dots).

\section{Conclusions}

Through price decomposition, the authors conclude that Greece milk price time series become more seasonal and cyclical. By considering the intense type of milk production in Greece, the authors believe that this is attributed to price convergence between the Greek milk price and EU milk price. Generally, the seasonality of the milk price has increased in the post-2004 period. The authors also note that the cycles of the examined countries have increased in number and in amplitude and that this is due to response to market signals. The period of the cycles remains rather stable pre and post-2004. This is in contrast with the literature which notes that the cycles become smaller (Bergmann et al., 2015). Also, the German milk price has two cycles in the post-2004 period. One cycle is behaving as the literature has noted, but the second cycle is very small in period and the authors believe it is due to the insemination decision the farmer makes in the duration of the year. Thus, the period of the second cycle is similar to the time needed for a cow to give birth. This cycle is due to supply response to yearly market signals. The authors also try to connect the cycles of the milk price with the milk production. The results show that the cycles present in the pre-2004 period are due to milk quota increase and only after 2004 the cycles seem to be independent of the milk quotas. Greece also, does not follow 
the cycle pattern, after 2011, probably due to the financial crisis. Finally, a post sample forecast is given for the year 2017.

\section{References}

Bergmann, D., O'Connor, D. and Thummel, A. (2013) 'A decomposition analysis of the EU farm gate milk price', Paper presented at the 87th Annual Conference of the Agricultural Economics Society, University of Warwick, United Kingdom, 8-10 April [online] https://www.researchgate.net/publication/280716543_A_Decomposition_Analysis_of_the_EU _Farm_Gate_Milk_Price (accessed 13 June 2017).

Bergmann, D., O'Connor, D. and Thümmel, A. (2015) 'Seasonal and cyclical behavior of farm gate milk prices', British Food Journal, Vol. 117, No. 12, pp.2899-2913.

CAP Health Check (2008) 'CAP health check - impact assessment note no, 6', in Impact Assessment for the 2008 CAP "Health Check" [online] https://ec.europa.eu/agriculture/policyperspectives/impact-assessment/cap-health-check_el (accessed 3 June 2017).

Commandeur, F.J. and Koopman, J.S. (2007) An Introduction to State Space Time Series Analysis, Oxford Uni. Press, Oxford, pp.3, 9, 21, 55, 62, 89, 96, 159.

Court of Auditors (2001) 'Special report no 6/2001 on milk quotas, together with the commission's replies', Official Journal of the European Communities, No. 2001/C305/1.

Cuddington, J. (1992) 'Long run trends in 26 primary commodity prices', Journal of Development Economics, Vol. 39, No. 2, pp.207-227.

Doornik, J.A. (2009) An Object-Oriented Matrix Language Ox 6, Timberlake Consultants Press, London.

Durbin, J. and Koopman, S.J. (2012) Time Series Analysis by State Space Methods, pp.69-71, Oxford Uni. Press, Oxford.

Erten, B. and Ocampo, A.J. (2013) 'Super cycles of commodity prices since the mid-nineteenth century', World Development, Vol. 44, No. C, pp.14-30.

EU (2015) The EU Milk Sector Prepares for the End of Milk Quotas, European Commission Press Release, Brussels [online] http://europa.eu/rapid/press-release_IP-15-4694_en.htm (accessed 3 June 2017).

EU Quota Table (2017) Use of the Annual Milk Quota - Deliveries [online] https://ec.europa. eu/agriculture/sites/agriculture/files/milk-quota-end/detailed-figures_en.pdf (accessed 3 June 2017).

EU Report (2013) Report of the Conference 'The EU Dairy Sector: Developing beyond 2015 [online] http://ec.europa.eu/agriculture/sites/agriculture/files/events/2013/milkconference/report_en.pdf (accessed 3 May 2017).

European Commission Press Releases [online] http://europa.eu/rapid/press-release_IP-11-1204_en. htm?locale=en (accessed 3 May 2017).

European Milk Market Observatory (2017) [online] https://ec.europa.eu/agriculture/marketobservatory/milk_en (accessed 3 May 2017).

Eurostat (2017) Eurostat Database [online] http://ec.europa.eu/eurostat/data/database (accessed 16 November 2019).

Forero, P.F. (2012) 'Estimating state space models through maximum likelihood', Econometric Methods II TA Session 4 [online] http://www.kris-nimark.net/pdf/Handout_S4.pdf (accessed 8 December 2019).

Hansen, B.G. and Li, Y. (2017) 'An analysis of past world market prices of feed and milk and predictions for the future', Agribusiness, Vol. 33, pp.175-193, doi:10.1002/agr.21474.

Harvey, A.C. (1993) Time Series Models, 2nd ed., p.161, MIT Press, Cambridge.

Harvey, C.A. (1989) Forecasting, Structural Time Series Models and the Kalman Filter, Cambridge University Press, Cambridge. 
Harvey, I.D., Kellard, M.N., Madsen, B.J. and Wohar, E.M. (2012) Trends and Cycles in Real Commodity Prices: 1650-2010, Discussion Paper Series, Australian National University.

Hunt, T. and Kern, M. (2012) 'The end of the old US dairy price cycle', Rabobank Industry Note, No. 355, Rabobank International, Utrecht.

Jongeneel, R., Burrell, A. and Kavallari, A. (2011) Evaluation of CAP Measures Applied to the Dairy Sector, pp.3, 73, 76, 77, 81, 89, 90, 102, 109, 110,111, 114, 115, 116, 122, Wageningen UR (University \& Research Centre).

Koopman, J.S., Harvey, C.A., Doornik, A.J. and Shephard, N. (1995) STAMP: Structural Time Series Analyzer, Modeller and Predictor, Timberlake Consultants, London, UK.

Koopman, J.S., Harvey, C.A., Doornik, A.J. and Shephard, N. (2010) STAMP 8.3: Structural Time Series Analyzer, Modeller and Predictor, Timberlake Consultants, London, UK.

Ladiray, D., Mazzi, L.G. and Sartori, F. (2003) Statistical Methods for Potential Output Estimation and Cycle Extraction, pp.6, 25, 26, 32, 38, 41, European Commission, Brussels.

Mills, T. and Patterson, K. (2009) Palgrave Handbook of Econometrics: Volume 2: Applied Econometrics, 394pp, Palgrave Macmillan Ltd, Basingstoke, UK.

Nicholson, F.C. and Stehpenson, W.M. (2015) 'Milk price cycles in the U.S. dairy supply chain and their management implications', Agribusiness, Vol. 31, No. 4, pp.507-520, doi:10.1002/agr.21416.

O'Connor, D., Bergmann, D. and Keane, M. (2015) 'The challenges posed by price volatility in the EU dairy sector', in Agrarian Perspectives XXIV. Global Agribusiness and Rural Economy Proceedings of the 24th International Scientific Conference, Prague, Czech Republic, 16-18 September, pp.18-33.

OECD-FAO (2009) OECD-FAO Agricultural Outlook 2009, 184pp, OECD Publishing.

Pfaffenzeller, S. (2002) Forecasting the Price of Wheat and Other Commodities, PhD thesis, University of Nottingham.

Reinhart, M.C. and Wickham, P. (1994) 'Commodity prices: cyclical weakness or secular decline?', IMF Staff Papers, Vol. 41, No. 2, pp.175-213.

Reinsel, C.G. (2012) Elements of Multivariate Time Series Analysis, 192pp, Springer Science \& Business Media, New York, NY.

Rezitis, N.A., Ntinou, A. and Pachis, D. (2015) 'Investigating the international prices of wheat and rice', Agricultural and Food Economics, Vol. 3, No. 16 [online] https://doi.org/ 10.1186/s40100-015-0035-4.

Rezitis, N.A. and Sassi, M. (2013) 'Commodity food prices: review and empirics', Economics Research International, Vol. 2013, p.15, Article ID: 694507.

Skarżyńska, A., Abramczuk, Ł., Augustyńska-Grzymek, I., Czułowska, M., Idzik, M., Konrad Jabłoński, K. and Żekało, M. (2013) Projection of Income for 2015 for Selected Agricultural Products, Institute for Agriculture and Food Economics - National Research Institute. Nr. 88. 1, pp.35-38 [online] https://www.ierigz.waw.pl/publikacje/raportyprogramu-wieloletniego-2011-2014/1386939522 (accessed 13 June 2017).

Symeonidis, F. (2017) Greek Milk Price Decomposition, Master thesis, Hellenic Open University.

Trouvé, A., Dervillé, M., Gouin, D-M., Pouch, T., Briot, X., Fink-Kessler, A., Kroll, J-C., Lambaré, P., Rat-Aspert, O. and Jongeneel, R. (2014) Étude sur les mesures contre les déséquilibres de marché: Quelles perspectives pour l'après quotas dans le secteur laitier européen?, pp.1, 4, 9, 12, 13, 16, 24, 25, 26, 29, 30, 32, 35, 36, 37, Ministère de l'Alimentation de l'Agriculture et de la Pêche et FranceAgriMer, Paris.

Weber, A.S. and Hansen, H. (2014) Can a Monitoring Agency Efficiently Regulate the EU Milk Market?, Working Paper Available [online] http://literatur.thuenen.de/digbib_extern/ dn054618.pdf (accessed 3 June 2017). 


\section{Notes}

1 The European Milk Market Observatory was announced in September of 2013 at the conference 'The EU dairy sector: developing beyond 2015' (EU Report, 2013) and begun its operation in April of 2014 (Weber and Hansen, 2014). Its main role - as it will be also shown later below - is to increase the transparency and the dissemination of the information of the milk market data (European Milk Market Observatory, 2017).

2 Milk quotas where finally lifted in April of 2015 (EU, 2015) though a long-lasting process of soft landing (CAP Health Check, 2008). A scenario planed well ahead 2008, in Agenda 2000 Reform (Trouvé et al., 2014). In the soft landing scenario, there is a $1 \%$ increases per annum in the milk quota of the MS, starting 2009/2010 until 2013/2014. Italy was the only exemption which had 5\% increase in 2009 (OECD-FAO, 2009). By 2004, the total milk volume produced was below the ceiling allowed by the quotas (Jongeneel et al., 2011). Only five MS were reaching the quota ceiling in 2009-2010 production year (Jongeneel et al., 2011; EU Quota Table, 2017).

3 RMSE is root of mean square error (MSE), the latter is calculated through the Kalman filter. In simple words, RMSE is what SD is to the mean, but to the regression line.

4 CUSUM - cumulated sum of the standardised prediction errors. The null hypothesis is that the model is stable. The critical lines are given by $\pm\left[0.85 T^{\frac{1}{2}}+1.7 / T^{\frac{1}{2}}\right]$ where $t=1 \ldots T$ (Koopman et al., 1995). The critical lines increase with time due to uncertainty. 